\title{
Psychological features \\ of perception and understanding \\ of the text by adolescents
}

L. G. Zhedunova ${ }^{1}$, N. N. Posysoev ${ }^{2}$

${ }^{1}$ Yaroslavl State Pedagogical University named after K. D. Ushinsky

${ }^{2}$ Institute of Education Development

DOI: $10.18255 / 1996-5648-2021-3-444-451$

Research article

Full text in Russian

The article deals with the problem of perception and understanding of the text by adolescents. The difficulties associated with partial perception and, accordingly, the inability to perceive the text in full are analyzed. The authors substantiate the expediency of the formation of the ability to decentrate in children based on the material of academic disciplines.

Keywords: text; decentration; subjective image; cognitive styles; categorical scales

\section{INFORMATION ABOUT AUTHORS}

\author{
Zhedunova, Lyudmila G. E-mail: lzhedunova@mail.ru \\ Doc. Sc. (Psychology), Professor \\ Posysoev, Nikolay N. | E-mail: ardat54@mail.ru \\ Cand. Sc. (Psychology), Associate Professor
}




\section{Психологические особенности \\ восприятия и понимания \\ текста подростками}

Л. Г. ЖЖедунова ${ }^{1}$, Н. Н. Посысоев ${ }^{2}$

${ }_{1}^{1}$ Ярославский государственный педагогический университет им. К. Д. Ушинского
${ }^{2}$ Институт развития образования

DOI: $10.18255 / 1996-5648-2021-3-444-451$

УДК 159.9

Научная статья

Полный текст на русском языке

В статье рассматривается проблема восприятия и понимания текста подростками. Анализируются трудности, связанные с парциальным восприятием и, соответственно, неспособностью воспринимать текст в полном объеме. Авторы обосновывают целесообразность формирования способности к децентрации у детей на материале учебных дисциплин.

Ключевые слова: текст; децентрация; субъективный образ; когнитивные стили; категориальные шкалы

\section{ИНФОРМАЦИЯ ОБ АВТОРАХ}

\begin{tabular}{c|l} 
Жедунова, Людмила Григорьевна & $\begin{array}{l}\text { E-mail: lzhedunova@mail.ru } \\
\text { Доктор психологических наук, профессор }\end{array}$ \\
Посысоев, Николай Николаевич & $\begin{array}{l}\text { E-mail: sardat54@mail.ru } \\
\text { Кандидат психологических наук, доцент }\end{array}$
\end{tabular}

Анализ успешности понимания текста подростками по данным международных исследований показывает, что при достаточно высокоразвитой способности извлекать информацию у подростков недостаточно сформирована способность интегрировать и интерпретировать эту инорормацию [1]. Мы полагаем, что это обусловлено особенностями восприятия текста и прежде всего тем, что оно носит нецелостный, парциальный характер.

Текст (его восприятие и понимание) - междисциплинарный объект исследования. Это обусловлено как многогранностью, многофункциональностью самого текста, сложностью его структурно-уровневой организации, так и неоднозначностью и разнообразием психологических стратегий взаимодействия с ним. В зависимости от того, что является предметом изучения, (C) Жедунова Л. Г., Посысоев Н. Н., 2021

Статья открытого доступа под лицензией СС ВY (https://creativecommons.org/licenses/by/4.0/) 
Жедунова Л. Г., Посысоев Н. Н.

внимание исследователей направлено либо на текст и его характеристики: целостность, членимость, завершенность, связность - содержательный аспект либо на особенности коммуникации автора текста и субъекта, контактирующего с ним - процессуальный аспект. В статье мы остановимся на исследовании психологических механизмов, обеспечивающих полноту восприятия текста.

В настоящее время исследования в области восприятия и понимания текста, особенно художественного, в большей степени акцентируют внимание на понимании текста. Е. Н. Зарецкая, в частности подчеркивает, что «текст - коммуникативная структура, которая предназначена для понимания» [2, с. 301], т. е. он должен быть понятен читающему. Без воспринимающего субъекта текста нет, есть только «тело текста» (2, с. 302). При этом процессы восприятия в большей степени рассматриваются как часть или этап понимания, что, на наш взгляд, вносит определённые ограничения в понимание психологических механизмов, лежащих в основе целостного и объемного понимания текста. В последнее время в отечественной психологической науке появился ряд исследовательских работ (Е. В. Левченко, 2000, 2003; Л. В. Ширинкина, 2003, 2004), в которых предложена трехкомпонентная модель восприятия текста, выделены стратегии восприятия и понимания, описана френоменология [3-5]. В исследованиях американских ученых восприятие и понимание текста осуществляется в контексте исследований подростковой грамотности (E. Birr Moje, M. Overby, Nicole Tysvaer, and Karen Morris, 2008); в контексте формирования метадискурсивности подростков (D. Stockdill, E. Moje, 2017). В фрокусе внимания исследователей - мотивы чтения подростков, влияющие на особенности восприятия и понимания текста, а также средовые (социокультурные) фракторы [6].

Таким образом, собственно перцептивные механизмы, обеспечивающие полноту и целостность восприятия текста в настоящее время недостаточно исследованы. В связи с этим актуальным остается вопрос, какие перцептивные способности целесообразно формировать у учащихся для повышения качества взаимодействия ребенка с текстом.

Первичный контакт читателя с текстом как с некоторой внешней по отношению к субъекту реальностью обеспечивается процессами восприятия (формированием субъективного образа текста). А. Н. Леонтьев полагал, что в восприятии, как и в любом психическом акте, человек воспроизводит мир в образе. Собственно «... проблема восприятия ставится как проблема построения в сознании индивида многомерного образа мира, образа реальности» [7, с. 254]. Характеристики содержания этого образа, его ментальная репрезентация обеспечивают возможность адекватной ориентации в окружающей среде и в тексте.

По отношению к мышлению и пониманию восприятие является базовой функцией, и в этом отношении субъективный образ - это единственная реальность, с которой имеет дело субъект. Существенной характеристикой 
образа является его полимодальный характер, то есть в его формировании участвуют все органы чувств. В соответствии с этим текст может быть предъявлен в разных модальностях (аудиальная, визуальная, кинестетическая). В исследованиях В. Ф. Петренко, посвященных семантическому анализу чувственного образа, образ рассматривается как своеобразное перцептивное высказывание о мире [8].

Репрезентация любого конкретного события становится возможной благодаря имеющемуся у субъекта образу мира. Образ мира генерирует познавательные гипотезы постоянно. Эти гипотезы превращают данные, полученные от органов чувств, в материал, из которого строится образ мира. В контексте исследования процесса речевосприятия А. А. Леонтьев предложил использовать понятие образ содержания текста, рассматриваемый как процесс понимания, взятый с его содержательной стороны [9]. Результаты исследований свидетельствуют о наличии выраженных стратегий чтения в зависимости от характера содержания [9].

В работах Д. А. Леонтьева обозначается взаимодействие трех фракторов в ситуации контакта человека и искусства. Три фактора имеют отношение, собственно, к личности (ценностно-смысловая сорера, потребности и художественная компетентность), три - к произведению искусства (смысловое содержание, чувственная эстетическая структура и рекламно-информационная оболочка), три фрактора характеризуют ситуацию (культурный фрон, групповые нормы и конкретная ситуация взаимодействия) [10].

Образ мира зарождается и формируется в деятельности, а всякая деятельность оставляет в психике следы, интегрированные в субъективном опыте личности. Субъективный опыт имеет структурно-уровневую организацию и состоит, по мнению Е. Ю. Артемьевой из трех уровней. Первый, самый поверхностный, слой субъективного опыта, соотносимый с поверхностными структурами образа мира, - перцептивный мир. Элементы этого уровня модальны, и в этом отношении он к образу восприятия. Тем не менее перцептивный мир сложнее, так как близок регулируется системой значений и смыслов. Таким образом, функционирование этого слоя неотделимо от более глубоких слоев субъективного опыта.

Следующий слой субъективного опыта - семантический, в этом слое следы деятельностей зафиксированы в виде многомерных отношений. Этот слой Е. Ю. Артемьева называет «картиной мира», рассматривая его как переходный между поверхностными и ядерными структурами образа мира [11]. О нем писал А. Н. Леонтьев: «...Мы можем говорить о системе отношений, о «целом», о специальном, самом глубоком измерении мира - пятом квазиизмерении, том смысловом поле, которое является одной из основных образующих амодального образа мира» [7, с. 256].

Самый глубокий слой субъективного опыта - слой амодальных структур - соотносим с ядерными структурами образа мира. Этот слой наиболее 
Жедунова Л. Г., Посысоев Н. Н.

статичен, его перестройка возможна лишь как результат действия, «сдвигающего» смыслы.

Если элементами первого уровня субъективного опыта являются образы объектов, то элементы второго и третьего уровней - образы отношения к объектам. Очевидно, что отношение к объектам фрормируется на основе системы общественно выработанных значений (семантики) и личностных смыслов, возникающих в процессе индивидуального опыта (индивидуальное значение значения - психосемантика).

Семантический уровень субъективного опыта содержит категориальные структуры, в рамках которых оценивается любое воспринимаемое событие. Их содержание составляют биполярные субъективные шкалы-конструкты, число и системная организация которых определяет простоту \ сложность познавательной сферы личности. Эти шкалы выполняют две фрункции одновременно: обобщение (установление сходства) и противопоставление (установление различия) в условиях оценки тех или иных объектов (прежде всего других людей и самого себя).

Исследуя психологические особенности смыслового восприятия текста, Д. Г. Артамонов подчеркивает: «... мир отражается в сознании, и изображение возвращается через литературу, иными словами, существуют аналогии между структурой бытия и структурой литературы» далее там же - «у читателя его понимание произведения не превзойдет его понимания бытия» [12, с. 256]. Оба процесса осуществляются параллельно.

Мы полагаем, что широта и разветвленность системы категориальных шкал лежит в основе успешности понимания любого текста, так как обеспечивает множественность и вариативность оснований для дифрееренциации и интеграции воспринимаемой информации. С целью проверки этого предположения нами было проведено специальное пилотное исследование.

Цель исследования - выявление зависимости успешности понимания текста от степени выраженности стилевых характеристик познавательной сфреры личности: полезависимости - поленезависимости, аналитичности - синтетичности. Выбор данных характеристик обусловлен следующим: мы полагаем, что полезависимость - поленезависимость позволяет определить степень контекстуальной включенности подростков при работе с текстом, аналитичность - синтетичность характеризует их умение выделять большее или меньшее количество оснований для дифференциации и классификации групп объектов при работе с информацией, содержащейся в тексте.

В исследовании приняли участие 30 подростков (14-15 лет), учащиеся общеобразовательных школ г. Ярославля. Испытуемым были предложены три задания.

Первое задание было направлено на исследование полезависимости - поленезависимости. Использовалась методика «Включенные фригуры» (Witkin, Oltman, Raskin, Karp, 1971) [13]. Второе задание использо- 
валось для определения аналитичности - синтетичности. Суть методики состоит в сортировке карточек со словами на группы по самостоятельно выделяемым самим субъектом критериям. Третье задание было направлено на понимание текстов и выполнение к ним ряда заданий. Успешность понимания текстов оценивалось на основании степени сорормированности трех компетенций:

Компетенция 1. «Способность интегрировать и интерпретировать информацию». Она включает:

- умение понимать чувства, мотивы, характеры героев,

-умение устанавливать связи между событиями или утверждениями (тезис - пример),

- умение понимать информацию, представленную в графической форорм;

Компетенция 2. «Способность осмыслять и оценивать содержание и фрорму текста». Она включает:

- умение обнаруживать противоречия, содержащиеся в разных частях текста,

- умение понимать назначение структурной единицы текста.

Компетенция 3. «Способность использовать информацию из текста». Она включает:

- умение выявлять связь между прочитанным и современной реальностью.

Математическая обработка результатов осуществлялась с помощью корреляционного анализа с использованием коэффициента ранговой корреляции Спирмена. Результаты корреляционного анализа представлены в таблице 1.

Таблица 1

\section{Взаимосвязь успешности понимания текста и стилевых характеристик познавательной сферы личности}

\begin{tabular}{|l|c|c|c|c|}
\hline \multirow{2}{*}{ Компетенции } & \multicolumn{2}{|c|}{$\begin{array}{l}\text { Полезависимость - } \\
\text { Поленезависимость }\end{array}$} & \multicolumn{2}{|c|}{$\begin{array}{c}\text { Аналитичность - } \\
\text { Синтетичность }\end{array}$} \\
\cline { 2 - 5 } & $\mathrm{rS}$ & $\mathrm{p}$ & $\mathrm{rS}$ & $\mathrm{p}$ \\
\hline $\begin{array}{l}\text { Умение интегрировать } \\
\text { и интерпретировать } \\
\text { информацию }\end{array}$ & $-0,63$ & 0,042060 & 0,57 & 0,299744 \\
\hline $\begin{array}{l}\text { Умение осмьслять и оце- } \\
\text { нивать содержание и фор- } \\
\text { му текста }\end{array}$ & $-0,11$ & 0,692281 & 0,27 & 0,300053 \\
\hline $\begin{array}{l}\text { Умение использовать ин- } \\
\text { формацию из текста }\end{array}$ & $-0,02$ & 0,933977 & 0,07 & 0,783386 \\
\hline $\begin{array}{l}\text { Успешность понима- } \\
\text { ния текста }\end{array}$ & $-0,61$ & 0,049619 & $-0,03$ & 0,91865 \\
\hline
\end{tabular}


Жедунова Л. Г., Посысоев Н. Н.

Как видно из таблицы, ведущая компетенция - умение интегрировать и интерпретировать информацию - отрицательно связана с поленезависимостью и положительно с аналитичностью. Иными словами, восприятие текста осуществляется под влиянием видимого поля и ориентировано в большей степени на различия, чем на сходство. Таким образом, способность к диффреренциации информации, выбору нескольких оснований для дифференциации, а также высокая контекстуальная включенность обеспечивают успешность понимания текста.

На наш взгляд, в основе дифреренциации и интеграции лежит способность к децентрации. Понятие децентрации - одно из ключевых в концепции генетической эпистемологии Ж⿱. Пиаже, которое он ввел его для объяснения особенностей когнитивного и морального развития личности $[14,15]$. Децентрация лежит в основе преодоления эгоцентризма, способности субъекта к принятию роли или взглядов другого человека, способности менять позицию наблюдения и рассматривать любую ситуацию с разных точек зрения, иными словами, вставать на позицию другого, видеть мир вариативно (сверху, снизу, слева, справа, плоско, объемно и т. п.).

Первично децентрация формируется благодаря детской активности в пространстве игровой деятельности. Влезть на дерево, забраться на крышу, спуститься в пещеру, глубокую яму, поплавать с маской под водой. В результате подобных игр ребенок начинает осознавать, что изменение его пространственного положения изменяет видимый мир, развивается способность к транспозиции позиции наблюдения. В более старшем возрасте на базе механизма децентрации формируется эмоциональный интеллект, определяющий успешность распознавания и идентификации своих и чужих переживаний. Это помогает ему лучше понимать себя и выстраивать дифференцированные отношения с осознанием собственных границ. В процессе школьного обучения механизм децентрации может быть сорормирован или доформирован на любых уроках, на разном материале [16]. На фризкультуре - через телесность, на естественных науках - через понимание неоднозначности и многообразия явлений природы, на уроках словесности - через вариативность трактовок одного и того же произведения, возможность пережить то или иное событие с позиции разных персонажей.

Таким образом, создание ситуаций, мотивирующих на изучение дискурсов разных областей знания, интегрирование их в свой личный опыт, приводит к изменению представлений ребенка об абсолютности своего положения в мире вещей и людей, способствует расширению категориальной структуры сознания и, соответственно, успешности восприятия текста.

\section{Ссылки}

1. PISA 2018 Assessment and Analytical Framework. Paris: OECD Publishing, 2019. 308 p. 
2. Зарецкая Е. Н. Риторика: Теория и практика речевой коммуникации. М.: Дело, 2002.480 с.

3. Левченко Е. В. Перспективы современных исследований восприятия // Творчество в образовании, культуре, искусстве. Пермь: ПГИИК. 2000. С. 99-101.

4. Левченко Е. В., Ширинкина Л. В. Восприятие текста как психологическая проблема // Стереотипность и творчество в тексте: межвуз. сб. науч. тр. / Перм. унт. Пермь, 2003. Вып. 6. С. 32-48.

5. Ширинкина Л. В. Восприятие текста как психологический феномен. Пермь, 2004. 250 c.

6. Stockdill D, Moje E. B. Adolescents as readers of culture, history, economics, and civics: The disconnect between student interest in their world and social studies schooling. Ann Arbor: University of Michigan; 2017. 36 p.

7. Леонтьев А. Н. Психология образа // Вестник МГУ. Сер. 14. Психология. 1979. № 2. C. 3-14.

8. Петренко В. Ф. К вопросу о семантическом анализе чувственного образа // Восприятие и деятельность. М., 1976. С. 268-292.

9. Леонтьев А. А. Основы психолингвистики. М.: Смысл; СПб.: Лань, 2003. 287 с.

10. Леонтьев Д. А. Психология смысла: природа, строение и динамика смысловой реальности. 2-е изд., испр. и доп. М.: Смысл, 2003. 487 с.

11. Артемьева Е. Ю. Основы психологии субъективной семантики. М.: Наука Смысл, 1999. 350 с.

12. Артамонов Д. Г. Психологические особенности процесса смыслового восприятия текста // Северо-Кавказский психологический вестник. 2013. № 11(4). C. $15-18$.

13. Role of the field-dependent and field-independent cognitive styles in academic evolution: A longitudinal study / H. A. Witkin [et all.] // Journal of Educational Psychology. 1977. № 69 (3). P. 197-211.

14. Пиаже Ж. Генетическая эпистемология. СПб.: Питер, 2004. 160 с.

15. Пиаже Ж. Психология интеллекта. Питер, 2003. 192 с.

16. Ж⿱㇒едунова Л. Г., Посысоев Н. Н. Исследование когнитивной сореры воспитанников детских домов // Ярославский педагогический вестник. 1999. № 1 (19). С. $114-121$. 